\title{
Breve historiografia do gênero musical missa no Brasil e as três missas nordestinas do movimento armorial
}

Brief historiography of the Mass musical genre in Brazil and the three northeas-

tern Masses of the armorial movement

\author{
Carlos Eduardo Brandão Calvani*
}

https://doi.org/10.29327/256659.12.2-14

\section{Resumo:}

O presente artigo é parte de uma pesquisa maior que visa mapear as missas compostas fora dos ambientes eclesiásticos. O texto apresenta uma breve historiografia do gênero no Brasil a partir dos esforços de inculturação pós-Vaticano II sem a pretensão de oferecer um estado da arte completo, mas com o intento de divulgar e informar a pesquisadores/as interessados/as no assunto, especialmente liturgistas, músicos e pastoralistas, a grande fecundidade da cultura brasileira e seu potencial de resistência à globalização gospel que atinge também certos setores do catolicismo brasileiro com os "padres cantores". O artigo apresenta também um panorama do Movimento Armorial e destaca três missas compostas por autores ligados a esse movimento.

Palavras-chave: Missas brasileiras. Música nordestina. Movimento Armorial. Cultura nordestina.

\section{Abstract:}

This article is part of a larger research aimed at mapping the Masses composed outside ecclesiastical environments. The text undertakes a brief historiography of such genre in Brazil based on some post-Vatican II inculturation efforts without the intention of offering a state of the art, but rather, with the intention of disseminating and informing researchers interested in the subject, especially liturgists, musicians and pastoralists, about the great fertility of Brazilian culture and its potential to resist the globalized trend of "gospel praise", which also affects certain sectors of Brazilian Catholicism with the "singing Fathers". The article also presents an overview of the Armorial Movement and highlights three Masses composed by authors linked to this movement.

Keywords: Brazilian Masses;Brazilian Northeastern music; Armorial Movement;Brazilian Northeastern culture.

\footnotetext{
*Bacharel em Teologia (Seminário Teológico de Londrina - 1990) e pela Faculdade Unidade de Vitória (2014), Mestrado (1994) e Doutorado (1998) em Ciências da Religião (UMESP). Professor no Núcleo de Graduação em Clências da Religião e no Programa de Pós-Graduação em Ciências da Religião da UFS. E-mail: cecalvani@hotmail.com
} 


\title{
Introdução:
}

\author{
"A fé vem pelo ouvir" \\ (Apóstolo Paulo - Romanos 10.17)
}

O presente artigo é parte de uma pesquisa maior, de mapeamento de missas musicadas na contemporaneidade principalmente fora da tutela eclesiástica. A título de esclarecimento, lembro que o termo "missa" pode ser compreendido em dois sentidos: (a) o religioso stricto sensu (eclesiástico, teológico e dogmático) que compreende a missa como o culto principal da Igreja, com suas partes fixas e móveis; e (b) o estético (não-eclesiástico) no qual "missa" é um gênero próprio da música que se utiliza das partes fixas da missa eclesiástica com bastante liberdade, inclusive textual. Portanto, a expressão "missa", atualmente pode ser compreendida a partir dessas duas óticas: a religiosa e a estética.

O presente texto tem caráter informativo, na medida em que pretende divulgar três missas nordestinas compostas por autores vinculados ao Movimento Armorial, e pouco conhecidas por músicos, musicistas e liturgistas mais jovens.

\section{Missa: da função eclesiástica ao gênero musical}

O gênero "missa" nasceu no ambiente eclesiástico, mas atualmente se emancipou do mesmo. Contudo, tal emancipação não é radical, pois alguns músicos eventualmente compõem missas com funções litúrgicas, enquanto outros utilizam o texto do missal para experimentações musicais, na contramão de um tem-po em que a Igreja subordinava a linguagem musical a seus interesses. Se antes a música servia ao texto litúrgico, atualmente, é o texto da missa que serve às experimentações musicais. Desde a Idade Média, mas sobretudo no final do século XVII, a junção do texto litúrgico com a linguagem musical se desenvolve em prol da valorização da própria música e tudo o que a compõe (melodia, harmonia, ritmo) e as particularidades internas de cada uma dessas instâncias. $\mathrm{Na}$ modernidade, o texto da missa se descola e se desloca de seu contexto religioso, e por extensão "decola", ganhando forma própria, independente de ser autorizada ou não por alguma autoridade eclesiástica.

Não nos interessam aqui os detalhes rituais e teológicos da missa eclesiástica, propriamente, mas o gênero musical "missa". Um gênero musical pode ser identificado a partir de um conjunto de elementos estruturais que o compõem e 
que aproximam pessoas que reconhecem aquele conjunto como dotado de uma forma própria. Nesse caso propomos que o gênero "missa" comporta:

(a) a utilização da sequência tradicional da missa eclesiástica (Kyrie, Gloria, Credo, Sanctus/Benedictus/Hosana, Agnus Dei). A essa sequência podem ser introduzidas outras partes do rito;

(b) a predominância do latim (à exceção do Kyrie, sempre em grego, e de expressões hebraicas e aramaicas como Aleluia, Hosana e Amém); ultimamente, porém, sobretudo após o Vaticano II, há grande profusão de missas em outros idiomas;

(c) a adaptação métrica do texto à melodia de modo que possa ser cantado por solistas ou coro;

(d) uma identidade autoral, que lhe dá o caráter de obra completa, composta por uma pessoa que registra a partitura, ou por mais de uma, que registram a obra (é o caso da Missa dos Quilombos). Ou seja, a missa musicada tem uma identidade estética própria e às vezes também um conceito formal (valorização de uma etnia, de uma cultura minoritária ou um protesto político).

Ao privilegiar o "gênero musical missa", estamos seguindo pegadas abertas por Max Weber nos ensaios "Rejeições religiosas do mundo e suas direções" (Weber, 1982) e "Fundamentos racionais e sociológicos da música" (Weber, 1995).

Em linhas gerais, Weber observa que, no Ocidente a música passou por um processo de racionalização de tal apuro técnico que se tornou autônoma em relação à sua antiga subserviência à religião, e capaz inclusive de concorrer substutivamente com a mesma, porque

todas as religiões sublimadas da salvação focalizaram apenas o
significado, e não a forma, das coisas e atos para a salvação [e] des-
valorizaram a forma como contingente, como algo da criatura e que
a afastava do significado" (...) A arte assume a função de uma sal-
vação neste mundo, não importa como isto possa ser interpretado.
Proporciona uma salvação das rotinas da vida cotidiana, e especi-
almente das crescentes pressões do racionalismo teórico e prático.
(...). Aos olhos da religião, essa salvação é um reino de indulgência
irresponsável e um amor secreto (WEBER, 1982, p. 391).

Leopoldo Waizbort, tradutor e responsável pela "Introdução" da edição brasileira de "Os fundamentos racionais e sociológicos da música", esclarece:

Com o processo de racionalização e a conseqüente autonomização da arte, esta passa a possuir valores próprios, que acabam por competir com os valores da religião. Quanto mais autonomizada for 
a arte, maior será sua tensão com a religião, pois sua legalidade própria a desatrela do religioso. Assim está instituída a relação de tensão entre a esfera estética e a esfera religiosa. No estado atual do processo de racionalização - a modernidade -, tal tensão chegou a um ponto extremo, já que a arte assume a função de uma forma de redenção, papel que a religião reserva para si (e que a economia e a politica, por exemplo, usualmente não reclamam) (WAIZBORT in WEBER, 1995, p. 31).

Por extensão, assumimos nesse texto a perspectiva de que o processo de autonomia da música, sobretudo após o período das reformas eclesiásticas no Ocidente deflagrou inevitáveis tensões com a Igreja Católica Romana, principalmente no que diz respeito ao interesse de compositores por musicar o texto da missa eclesiástica. Apegada a formas antigas, a Igreja inicialmente não acompanhou tais desdobramentos e muitos compositores, cerceados em sua liberdade criativa pelos padrões autorizados de "música sacra", promoveram um movimento oposto. Já não devendo satisfações à Igreja, nem temendo ameaças de excomunhão, trouxeram as palavras da missa para o âmbito de domínio geral da música. A relação, portanto, se inverteu: agora o texto da liturgia é que serve à música, e não o oposto (a música como serva da liturgia). Se nem todas as novas formas de música contemporânea são consideradas "sacras" pela Igreja, nem por isso deixam de ser música "religiosa".

O desenvolvimento das artes musicais e o incentivo à música na reforma protestante (Deutsche messe e o Saltério de Genebra) levou o Concílio de Trento a promulgar em 1562 o Decretum de observandis et evitandis in celebrationeMissaeque proibiu a utilização de melodias "sedutoras e impuras", bem como o uso de instrumentos associados à música "mundana", autorizando somente o órgão como suave base harmônica. A partir de 1570 o Missal prescreve o emprego exclusivo do latim, a sucessão de partes fixas (Ordinário), os trechos que variam de acordo com o calendário litúrgico (Próprios), as que seriam cantadas pelo oficiante (bispo, padre ou diácono) e as que eram permitidas ao coro. Enfim, seja no catolicismo ou nas igrejas reformadas, a música strictu sensu sempre foi considerada "serva" da palavra, uma auxiliar a serviço do texto litúrgico ou da mensagem proclamada, o que de certo modo limitava experimentos musicais. Quanto mais próxima a vigilância institucional, maior também a vigilância dogmática e, consequente, menores as possibilidades de criatividade artística. São muitos os documentos oficiais da Igreja impondo limites e cerceamentos à produção musical de missas. Interessados podem consultar Tralesollecitudine, Papa Pio X, 
1903; Constituição Apostólica DivinisCultusSanctitatem, Papa Pio XI, 1928 e Encíclica MusicaeSacrae Disciplina, do Papa Pio XII, 1955.

Em todas as declarações oficiais da Igreja, prevaleceu durante muito tempo a mesma atitude e o mesmo adjetivo: a música deve ser "serva" da liturgia. A despeito disso, na modernidade, gradativamente os compositores perceberam que a música oferece oportunidade para múltiplas formas de expressão capazes de superar as restrições eclesiásticas e ganhar autonomia a partir de seus próprios valores internos, deixando de ser apenas um instrumento a serviço da ética religiosa, do dogma ou da instituição.

Esse processo de apuro das técnicas musicais colaborou para que alguns compositores se arriscassem a experimentações musicais com o texto, mas sem preocupações litúrgicas. Assim, ocorre uma inversão: se até então, muitos compositores obedeciam às expectativas eclesiásticas, compondo músicas "a serviço do texto litúrgico", agora é o texto litúrgico que serve como base e plataforma para o exercício de novas técnicas de composição e arranjo. É o caso de três famosas missas que, a despeito do grande reconhecimento que adquiriram nos círculos musicais, não têm qualquer intenção de serem aproveitadas como "missas litúrgicas" executadas durante um oficio religioso: a "Grande Missa em Dó menor, K 427" (Mozart), a "Grande Missa em Si menor BWV 232" (Bach) e a "Missa Solemnis Opus 123" (Beethoven). Essas obras ajudaram no processo de autonomização do gênero missa, pelo "deslocamento" da função litúrgica, abrindo espaço para descolamentos posteriores, como a "Grande missa de Réquiem opus 05" (Berlioz), a "Missa Canônica em Dó Maior" (Brahms).

\section{Missas musicadas ${ }^{1}$ no Brasil - breve historiografia}

As primeiras missas musicadas no Brasil são da época colonial, seguem padrões do barroco e do classicismo e refletem certa tensão entre influências das escolas italianas e germânicas. Medeiros (2014) considera que principais são a Missa Brevis de André Silva Gomes (1852-1844) em estilo rococó, para vozes e instrumentos, a "Grande Missa em Mi Bemol" e a "Missa em Fá", ambas do mineiro José Joaquim Lobo de Mesquita (1764-1805).

Já no Brasil-Império, a principal referência genuinamente brasileira é o padre José Maurício Nunes Garcia (1767-1830), filho de escrava alforriada e conhecido como "padre mulato". Reconhecendo seu talento, Dom João VI o nomeou 
mestre e organista da Capela Real, o mais alto cargo para um músico na época. Porém, a transferência progressiva de músicos ligados à antiga corte em Lisboa muito o prejudicou, pois constantemente tentavam afastá-lo, por racismo e inveja, alegando que naquele posto não deveria encontrar-se alguém "com defeito físico visível”, em alusão à sua ascendência negra. Não há espaço aqui para comentar suas principais missas - a "Missa de Nossa Senhora da Conceição" (1810), a "Missa Pastoril para a noite de Natal" (1811), a "Missa de Requiem" (1816), a "Missa de Nossa Senhora do Carmo" (1818) e a "Missa de Santa Cecília" (1826), mas desde que Mário de Andrade o considerou "o primeiro nome ilustre da música brasileira” (ANDRADE, 1980, p. 173), seu legado tem sido recuperado e valorizado através de diversas pesquisas, dissertações e teses (MATTOS, 1970; FIGUEIREDO, 2000; GOLDBERG, 2004: AFFONSO, 2005; COTTA, 2008; VIRMOND e NOGUEIRA, 2011; D'ACOL, 2015). Todas essas obras podem ser ouvidas no youtube ou em outras plataformas de streaming em gravações de coro e orquestra nacionais e internacionais

Ainda no Brasil Imperial, Francisco Manuel (1795-1865), compositor do Hino Nacional Brasileiro, compôs a "Missa em Mi Bemol" e Carlos Gomes (18361896), antes da ópera "O Guarani" (1870), compôs ao menos duas missas: a "Missa de São Sebastião" (1854) e a "Missa de Nossa Senhora da Conceição" (1859).

A Semana de Arte Moderna (1922) inspirou compositores a pesquisar ritmos e melodias "folclóricas" a fim de identificar elementos que apontassem para a construção de uma "brasilidade". Villa Lobos, Camargo Guarnieri e GuerraPeixe adotaram forte viés nacionalista, mas também dialogaram criativamente com tendências e experimentos dodecafônicos e atonais. Alguns atenderam às regras eclesiásticas (Osvaldo Lacerda, p.ex), enquanto outros se serviram do texto litúrgico para novas experimentações sonoras.

Após o Vaticano II as regras eclesiásticas se flexibilizaram bastante, dando oportunidade ao surgimento de missas em diversos idiomas. Antes mesmo do Vaticano II, o padre franciscano Guido Haazen criou no antigo Congo a "Missa luba" (1958) e no mesmo ano, no Brasil, Reginaldo Carvalho (ex-aluno do grupo nacionalista de Villa-Lobos) concebeu a "Missa Sertaneja" com diferentes ritmos nordestinos e letra em português com um texto coloquial ("a gente" em lugar de "nós" no Kyrie e no Agnus Dei e "CrenDeusPai" no Credo). Em 1964 Ariel Rami- 
rez criou a MisaCriolana Argentina. Tais expressões motivaram compositores brasileiros a voltar compor missas utilizando elementos da cultura popular. No anexo deste artigo, são elencadas algumas missas surgidas no Brasil no século XX. Dessa grande profusão criativa, algumas merecem breves comentários:

Em 1971, o maestro Carlos Alberto Pinto Fonseca compôs a "Missa Brasileira de Batuque e Acalanto" para coro e solistas. O texto utiliza latim e português e vários ritmos diferentes não necessariamente identificados com a "cultura afro" (marcha-rancho, vira-português, samba-canção e aboio). O Credo reproduz cantigas de roda folclóricas como "Tutu Marambá" e "Se esta rua fosse minha". Porém, sua recepção em outros campos foi prejudicada pelo fato de o próprio maestro declarar ser uma composição "técnica", concebida quando morou em Salvador, mas que ele mesmo, jamais frequentou qualquer culto afro, faltandolhe a percepção de que o modo de tocar os instrumentos no batuque ritual, bem como o idioma (ioruba, banto, etc) revelam a identidade do grupo (Nagô, AngolaCongo). Além disso, o modo de tocar os instrumentos no batuque, bem como o idioma (ioruba, banto etc) revela as hierarquias e os orixás invocados. Tais fatores levaram Fernandes (2004, p. 63) a considerar que essa missa, "muito mais do que resultado de um sincretismo religioso, é produto de uma estética nacionalista”.

Esse questionamento certamente está ligado ao título referencial dado à obra, pois o ouvinte não-iniciado em técnicas musicais e mais interessado nas influências culturais, espera exatamente o que a Missa, em sua partitura original, não apresenta: "não existem referências a orixás ou a melodias tradicionalmente associadas ao culto afro. A performance da obra não requer coreografias ou movimentos que lembrem as danças características de tais rituais" (FERNANDES, 2004, p. 62). A despeito disso, trata-se de obra de inegável qualidade musical, muito elogiada e bem recebida nos ambientes da música erudita. Em 2006 o percussionista Djalma Fonseca acrescentou notações para percussão e a missa foi gravada pelo Coro que leva o nome do compositor, com adequada percussão. ${ }^{2}$

Bem diferente esteticamente é a "Missa dos Quilombos" (1981), uma das mais emblemáticas produzidas no Brasil. Concebida entre setores do clero católico progressista, foi musicada por Milton Nascimento resultando em produto híbrido - é, ao mesmo tempo, missa e espetáculo performático. Enquanto missa stricto sensu, foi celebrada pela $1^{\mathrm{a}}$ vez no Quilombo da Serra da Barriga em Ala- 
goas e na semana seguinte na Praça do Carmo, na cidade do Recife, no local onde a cabeça de Zumbi dos Palmares foi exposta em 1695. A repercussão chamou a atenção da Sagrada Congregação para o Culto Divino e os Ritos, e o Vaticano proibiu sua celebração por quase uma década. Enquanto espetáculo, foi apresentada em 1989 nos Arcos da Lapa no Rio de Janeiro e 1992 em Santiago de Compostela, a convite da Prefeitura, como parte das "comemorações" dos 500 anos de colonização da América Latina. Em 2002 o grupo Cia Espaço Aberto montou espetáculo próprio com coreografias. Em 1995 voltou a ser celebrada como missa eclesiástica no Santuário Nacional de Nossa Senhora de Aparecida em São Paulo.

Compositores brasileiros têm sido muito criativos na produção de missas, algumas "inculturadas" (valorizando elementos de uma cultura ou região) outras "ecléticas" (combinando vários elementos). Não há espaço aqui para considerar a riqueza dessa produção. Apenas é possivel indicar algumas composições expressivas, mas pouco conhecidas fora dos ambientes de música erudita:

O compositor baiano Lindembergue Cardoso (1939-1989) deixou vasta obra musical. Feitosa (2010) analisou essa produção à luz do Concílio Vaticano II destacando, ao mesmo tempo a religiosidade e a heterodoxia no uso dos sistemas musicais. O pesquisador catalogou 110 peças. Dentre essa vasta produção destacam-se "Kyrie-Christi" (1971), "Os Atabaques de Pombagira” (1974), para coro misto a cappella, a Cantata natalina "Oxaguian" (1975) eaópera Lídia de Oxum (1988), para oito vozes solistas, coro e orquestra, estreada em 1995 sob a batuta do Maestro Júlio Medaglia em Salvador, além de seis missas. O envolvimento do compositor com a Igreja Católica levou a Arquidiocese de Salvador a convidá-lo a compor a "Missa João Paulo II na Bahia" (1980) com elementos da cultura musical do Nordeste, percussão de atabaques e agogô e coro de 672 vozes que acompanhou a missa oficiada pelo Papa em 07/07/1980 na capital baiana.

Jean Kleeb é natural de Santo André (SP) e radicado na Alemanha. Sua "Missa Brasileira" para coral e orquestra é eclética: Kyrie em ritmo de bossa- nova com muitas dissonâncias, suave percussão e influências jazzísticas ${ }^{3}$. O Gloria em latim é entoado em ritmo de samba e baião. Segue-se o Laudamus-te, ária operística acompanhada por viola de gamba. Indianische, um ritmo indigena, acompanha oGracias e o Domine Deus e a viola de gamba retorna junto a um címbalo no Quitollispeccatamundi, seguido pelo Quonian em ritmo de maracatu. O Credo inicia de modo tradicional, com influências do romantismo e, aos poucos 
sambaliza-se, terminando suavemente. O Sanctus é em ritmo de jazz (Takt 5/4) e os ritmos brasileiros voltam em profusão no Benedictus mesclando baião, maracatu e uma ária clássica. A Missa se encerra com o Agnus Dei, em acalanto. Obra de grande qualidade e que acompanha a proposta eclética e em alguns momentos "antropofágica" do compositor, tal como definida em seu próprio site - "uma ponte entre a música coral europeia e a intensidade rítmica da América do Sul".

KilzaSetti, musicóloga e Doutora em Antropologia Social (USP), foi aluna de Camargo Guarnieri (escola nacionalista). Atualmente trabalha como etnomusicóloga, desenvolvendo pesquisas sobre repertório caiçara, sistemas musicais de derivação africana e dos índios Mbyá-Guarany e música ritual do povo Timbira do Maranhão e Tocantins. A "Missa Caiçara" foi composta em 1990, por solicitação da Prefeitura de Peruíbe (SP). Mescla o texto em latim como pano de fundo, sobreposto pelo texto da missa em português, resultando em uma espécie de "tradução simultânea". A Missa foi concebida para ser executada dentro do ofício católico por coro e instrumentistas, mas a autora não encontrou nas igrejas da região músicos tecnicamente preparados para executá-la, embora a considere extremamente simples. Por fim, a estreia só veio a ocorrer em 1996 no II Festival de Música Sacra de São Paulo, com regência do maestro Samuel Kerr. Uma análise dessa obra, com entrevistas e partituras pode ser encontrada em Ribalta (2011).

\section{O Movimento Armorial e as Três missas nordestinas}

O Movimento Armorial surgiu em 1970 sob a liderança de Ariano Suassuna na condição de mentor estético, a partir de uma exposição de artes plásticas na Igreja de São Pedro dos Clérigos e um concerto com a Orquestra Armorial de Câmara. Ganhou apoio e adesão de artistas e escritores da região Nordeste do Brasil e da UFPE (Universidade Federal de Pernambuco) através do Departamento de Extensão Cultural da Pró-Reitoria para Assuntos Comunitários, da Prefeitura do Recife e da Secretaria de Educação e Cultura do Estado de Pernambuco. O objetivo era incentivar uma arte brasileira erudita (música, dança, literatura, artes plásticas, teatro, cinema e arquitetura) a partir das raízes populares do Brasil. Suassuna incomodava-se com os sinais do que hoje chamamos "globalização" e que na época era chamado "imperialismo cultural" (a invasão avassaladora da cultura "pop", especialmente norte-americana). O termo "armorial" aponta para o conjunto e o brilho de insígnias, estandartes, bandeiras e brasões de 
um povo, como as que vemos ainda hoje nas festas populares nordestinas. Conforme Suassuna,

\begin{abstract}
Comecei a dizer que tal poema ou tal estandarte de Cavalhada era 'armorial', isto é, brilhava em esmaltes puros, festivos, nítidos, metálicos e coloridos, como uma bandeira, um brasão ou um toque de clarim. Lembrei-me, aí, também, das pedras armoriais dos portões e frontadas do barroco brasileiro,e passei a estender o nome à escultura com a qual sonhava para o Nordeste. Descobri que o nome 'armorial' servia ainda para qualificar os 'cantares' do Romanceiro, os toques de viola e rabeca dos Cantadores - toques ásperos, arcaicos, acerados como gumes de faca-de-ponta, lembrando o clavicórdio e a viola-de-arco da nossa Música barroca do século XVIII (SUASSUNA, 1974, p. 9).
\end{abstract}

Além disso, Suassuna insista que a identidade do movimento derivava de sua localização espacial ou geográfica - o Nordeste - especialmente o rural, o sertão e a zona do agreste. O mentor esclarece outros elementos:

\begin{abstract}
A Arte Armorial Brasileira é aquela que tem como traço comum principal a ligação com o espírito mágico dos "folhetos" do Romanceiro Popular do Nordeste (Literatura de Cordel), com a Música de viola, rabeca ou pífano que acompanha seus "cantares", e com a xilogravura que ilustra suas capas, assim como com o espírito e a forma das Artes e espetáculos populares com esse mesmo Romanceiro relacionados (SUASSUNA, 1974, p. 4).
\end{abstract}

Medeiros (2014, p.52) observa a grande importância conferida pelo movimento à literatura de cordel e aos folhetos do romanceiro popular nordestino, com destaque para a xilogravura, o mamulengo (teatro de bonecos), os "autos" populares encenados ao ar livre "com personagens míticas, cantos, roupagens principescas feitas a partir de farrapos, animais misteriosos como o boi, o "pavão misterioso" e o cavalo-marinho do bumba-meu-boi. Na dramaturgia buscava um estilo de figurino e encenação tipicamente nordestinos tal como no "Auto da Compadecida".

Na música erudita, a principal referência do movimento foi Guerra-Peixe (1914-1993) que, desde os anos 50, já radicado no Recife, abandonou o dodecafonismo, passou a estudar ritmos nordestinos (maracatu, aboio, coco, frevo, xangô, baião, xote, xaxado, martelo-agalopado, etc.) e influenciou toda uma geração de novos compositores que foram seus alunos e revalorizam o pífano, a viola sertaneja, a guitarra ibérica, a rabeca e o marimbau. Além disso, os músicos "armoriais" empreenderam projetos acadêmicos de pesquisa documental e de campo, catalogando e identificando particularidades e origens desses ritmos e formas de cantar que rementem ao Brasil-Colônia. Conforme Queiroz, 
a música armorial é, portanto, uma música erudita, composta a partir de nossas raizes musicais arcaicas, tal como se acham preservadas no folclore nordestino. Tal como a música nordestina em geral, a música armorial é marcada por algumas constantes típicas, como a linguagem harmônica modal (uma reminiscência do cantochão trazido pelos missionários no Brasil Colônia), a presença da quarta aumentada e da sétima abaixada na linha melódica e os ritmos sincopados do coco e do baião, além de outros. Como se vê, não se pode dizer que o armorial representa o início de uma linguagem musical nordestina, já que ele constrói a sua música em cima de uma linguagem já existente no cancioneiro popular. $\mathrm{O}$ que ele representa é o início de uma linguagem musical erudita, que resgata as nossas verdadeiras raizes nordestinas (QUEIROZ, 2010, p. 16).

Todo movimento, caso não se institucionalize acaba por se dissipar a partir do falecimento de seus líderes. O mesmo aconteceu com o Movimento Armorial. Porém, essa "dissipação" não foi mera pulverização, mas polinização, uma vez que vários compositores nordestinos absorveram elementos "armoriais" em suas músicas e letras (o cearense Ednardo, os aboios do baiano Elomar, o Quinteto Violado, o Quinteto Armorial, o paraibano Zé Ramalho, o pernambucano Alceu Valença etc) e na literatura fantástica e/ou de cordel (o paraibano Jessier Quirino). No que se refere a "missas", o destaque maior é para as três principais obras que apresentamos a seguir:

\section{A Grande Missa Nordestina (Clóvis Pereira)}

O pernambucanoClóvis Pereira (1932-) foi aluno de Guerra-Peixe. Detalhes da biografia e entrevista com o compositor podem ser encontrados na pesquisa de Bezerra (2014). Envolveu-se com o Movimento Armorial já em 1970, a convite de Suassuna e declarou em entrevista recente: "Eu assisti junto com ele, caboclinhos, maracatus e outras manifestações do nosso folclore, e fui ficando impregnado dessa coisa de Nordeste e desviei o curso que eu tinha pra busca de música americana” (apud BEZERRA, 2014, p. 10).

A Missa Nordestina (1977) foi composta durante um semestre letivo por solicitação da UFPB (Universidade Federal da Paraíba), onde o compositor lecionava desde 1964 e ganhou reconhecimento internacional. Utiliza texto em latim e é escrita para coro, solistas (tenor e soprano) e Orquestra de Câmara (cordas, quinteto de madeiras e percussão). Após a primeira apresentação no teatro da 
UFPB, foi adaptada para Orquestra Sinfônica a pedido do BANORTE (Banco Nacional do Norte), que financiou também a gravação em estúdio, com um coral de 100 (cem) vozes, trompas, dois trompetes, dois trombones, uma tuba e um octavino. O álbum foi lançado com o título "Grande Missa Nordestina"4.

A música mescla diferentes ritmos nordestinos, tradição e contemporaneidade. O Kyrie e o Gloria trazem fortes influências gregorianas e alternâncias entre coro feminino, masculino, misto e solistas e no Gloria é marcante a introdução do terno de pífanos, ganzá e triângulo ao ritmo de baião. O Credo combina gregoriano e reminiscências de aboio, um modo lamentoso e lastimoso de tanger o gado, entoado por vaqueiros sertanejos. Para alguns pesquisadores da cultura popular, esse estilo é uma típica influência moura (CASCUDO, 2001, p.35) e que muito recorda as preces vespertinas islâmicas. O Benedictus é um típico acalanto, terno e introspectivo. Já no Agnus Dei são marcantes os traços de aboio lamentoso e da chamada "cantiga de cego", presente também ao final do Gloria.

\section{Missa de Alcaçus - Danilo Guanaes}

Composta em 1996 para solistas, coro e orquestra a pedido do Madrigal da Escola de Música da UFRN (Universidade Federal do Rio Grande do Norte) pelo prof. Danilo Guanaes (UFRN), a obra também adere à estética do Movimento Armorial. Embora seja paulistano, o maestro Danilo César Guanaes cresceu em Natal, onde foi aluno de Clóvis Pereira e onde também se graduou em Música na UFRN.

A Missa segue o texto em latim e as partes fixas do Ordinário e se caracteriza pela utilização de diferentes estilos medievais (cantilenas portuguesas, modinhas e acalantos). Os elementos populares estão presentes principalmente nas escalas e ritmos de aboio, baião, caboclinho, maracatu, repente e na orquestração com profusão de instrumentos tipicamente identificados com o interior nordestino, além de batuques africanos. Estreou no próprio ano de 1996 e, desde então, foi executada várias vezes por diferentes grupos orquestrais no Brasil e na Europa. O título da Missa remete ao povoado de Alcaçus, distrito de Nísia Floresta, na região metropolitana de Natal (RN), onde o autor desenvolveu pesquisas de campo junto a mulheres rendeiras e identificou muitas memórias populares de romanceiros ibéricos medievais bem como as influências do canto mouro. 
O Kyrie se inicia com um toque convidativo de viola respondido por violinos, com triângulo e zabumba que marcam o ritmo do coro. A percussão do Gloria lembra uma cavalgada. O Credo inicia com um canto lamentoso, típico das procissões populares nordestinas e adquire tons ora festivos, ora aboísticos mesclados com gregoriano e influências mozartianas no Deus de Deo. O contraste entre a sobriedade lamentosa do Crucifixus e a alegria do Et Ressuxit são de grande significação teológica. A obra tem também uma peculiaridade: a depender dos arranjos, pode se tornar uma Missa Brevis, pois os trechos do Ordinário são curtos (embora exijam muita técnica por parte de sopranos e barítonos) o que pode ser de muito aproveitamento para liturgistas. O registro da gravação pelo Madrigal da Escola de Música da UFRN pode ser acessado em https://www.youtube.com/watch?v=VJh3EqfwEOE com arranjos muito cuidadosos. Uma análise sociológica da obra pode ser encontrada em Medeiros (2014), que também oferece informações biográficas sobre o autor e outros detalhes de sua produção musical.

\section{A Missa Armorial (Lourenço F. Barbosa - "Capiba")}

Capiba (1904-1997) foi um dos mais conhecidos compositores de frevos de Pernambuco e um dos criadores do famoso bloco "Galo da madrugada", mas sempre esteve aberto a outros estilos. Compôs "Maria Bethãnia", gravada por Nelson Gonçalves, fundou um trio com Hermeto Pascoal e Sivuca e uma banda de jazz acadêmica. Aderiu ao Movimento Armorial e colaborou com o mesmo através de várias peças músicas como "Toada e Desafio", a suíte "Sem lei nem rei", a "Missa Armorial" e trilhas sonoras para teatro.

Composta em 1982, a missa tem estilo camerístico, utilizando cordas, duo de flautas e percussão pé-de-serra (zambumba, caixa e triângulo). Nesse sentido, distancia-se do estilo orquestral de Clóvis Pereira. Também utiliza o texto em latim e, com exceção do Benedictus, é sustentada por ritmos ligados ao forró nordestino (baião, xote e xaxado) com toques de frevo. Embora o título seja "Missa Armorial", a gravação do álbum com coro e a Orquestra Armorial regidos por Cussy de Almeida, levou o nome "Grande Missa Armorial" (https://www.youtube.com/watch?v=fI9S_iHyv3Y).

Os elementos tipicamente nordestinos são identificados logo no Kyrie em ritmo de xaxado. O Gloria, mais contido, é uma toada e seu primeiro compasso 
lembra as "cantigas de cego", transformando-se em baião com toques operísticos no solo barítono e posteriormente assumindo o tom lamentoso dos aboios. $\mathrm{O}$ Credo se inicia com diálogo entre solistas e coro e se desenvolve em ritmo de xote, cantiga de roda, toada de aboio e finaliza com baião, reunindo diversos elementos em torno de uma mesma confissão de fé. O Sancuts em baião é seguido por um suave Benedictus com inspirações bachianas. Uma mescla de baião e xaxado lembrando um forró nordestino finalizam a obra no Agnus Dei.

\section{Considerações finais}

Não é intenção deste texto sugerir músicas para atrair pessoas para a Igreja. O objetivo é valorizar elementos da cultura musical nordestina que, em qualquer igreja que leve a sério os sentidos teológicos atribuídos à palavra "inculturação" também devem ser considerados. Além disso, fazer sugestões litúrgicas é um atrevimento que pode cair em generalizações, pois a liturgia é um ato da comunidade de fé, e tudo o que for sugerido depende das condições próprias das comunidades (músicos, instrumentos adequados, solistas, coral, etc.). Ou seja, sempre há o risco de idealizar situações que jamais seriam reais em certas comunidades. Por outro lado, é preciso reconhecer que as comunidades eclesiásticas são grandes celeiros musicais, e que muitos músicos, cantores e cantoras no Brasil e em outros países descobriram e aprimoraram seus dons e talentos tocando e cantando em igrejas, e esse potencial não pode ser menosprezado.

Um estudo sobre missas "inculturadas" também pode trazer um grande desafio: perguntar-se o motivo pelo qual viramos as costas à imensa riqueza musical de nossas culturas regionais e às nossas raízes musicais ("arcaicas", diriam os armoriais). KilzaSetti, Jean Kleeb, Lindembergue Cardoso e os compositores armoriais, longe de se envergonhar dessas raízes "arcaicas", as tomaram como fonte de inspiração musical e se abriram a registros e estruturas que, embora não veiculadas nas grandes mídias, permanecem latentes e dormentes na memória musical de muita gente. Faltam-nos ainda "missas" pantaneiras, gauchescas, amazonenses, ribeirinhas etc, o que também colaboraria na resistência à globalização cultural imposta pelo capitalismo, o mercado fonográfico e a Indústria Cultural. Também é preciso estar atentos para o fato de que povos-vizinhos e irmãos já nos oferecem obras de grande qualidade (a MisaCriolla, a Misa Guarany, a Misa por Buenos Aires, a Missa equatoriana, a Missa Cubana de Pedro Triana e a Missa guatemalteca). 
Esse, porém, não é um problema somente musical, mas cultural. Os/as músicos/musicistas continuarão compondo, às vezes em inter-relação com as igrejas, outras vezes, de modo autônomo, sem preocupações mercadológicas ou propriamente eclesiásticas. Afinal, "toda boa dádiva e todo dom perfeito vêm do alto" (Tiago 1.17), e, ao receber esses dons e talentos, realizam a seu modo e à sua "forma" e estilo, o que a escritura cristã chama de "multiforme" graça de Deus: "Cada um viva conforme a graça recebida a serviço dos outros, como bons administradores das muitas formas da graça que Deus lhes concedeu" (I Pedro 4.10).

\section{Referências Bibliográficas}

ADORNO, Theodor.Introdução à Sociologia da Música: doze preleções teóricas. Trad.de Fernando Moraes Barros. São Paulo: Editora Unesp, 2011.

AFFONSO, Rodrigo Cardoso. Um Estudo sobre a Relação Texto-Música: os Ofícios Fúnebres de José Mauricio Nunes Garcia. Dissertação (Mestrado em Música). Rio de Janeiro: UNIRIO, 2005.

ALMEIDA, Ágata Yozhiyoka. Música, religião e morte: recorrências tópicas na Missa de Réquiem em mi bemol maior de Marcos Portugal. Dissertação (Mestrado em Música). São Paulo:Universidade de São Paulo, 2016.

ANDRADE, Mário de.Pequena história da música. $8^{\circ}$ ed. Belo Horizonte: Editora Itatiaia Limitada, 1980.

BEZERRA, José Renato Accioly. Grande Missa Nordestina de Clóvis Pereira: estudo para interpretação. Dissertação (Mestrado em Música). Natal: Universidade Federal do Rio Grande do Norte, 2014.

CAMPOS, Beatriz. Letra, música, performance e memória do racismo na Missa dos Quilombos. Dissertação (Mestrado em Literatura e práticas sociais). Brasília: UnB, 2017.

CANTON, Ciro. Das "velhas senzalas" às "novas favelas": a Missa dos Quilombos. Anais do XXV Simpósio Nacional de História. Fortaleza: ANPUH, 2009.

CASCUDO, Câmara. Mouros, Franceses e Judeus: três presenças no Brasil. $3^{\circ}$ ed. São Paulo:Global, 2001.

COTTA, André Guerra. Notas preliminares sobre o cantochão acompanhado na prática musical luso-brasileira dos séculos XVIII e XIX: o Hino a São João Batista de José Maurício Nunes Garcia. Per Musi.Belo Horizonte: UFMG, n. 18, jul.dez. de 2008.

DUARTE. Maria Dolores Pires do Rio. Travessia: a vida de Milton Nascimento. Rio de Janeiro: Record, 2006. 
FEITOSA, Marcos A. R. A Missa brevis de Lindembergue Cardoso: uma análise à luz do Concílio Vaticano II. Anais do XV Colóquio do Programa de Pós-Graduação em Música da UNIRIO. Rio de Janeiro, 2010.

FIGUEIREDO, Carlos Alberto. Editar José Maurício Nunes Garcia. Tese (Doutorado em Música). Rio de Janeiro: UNIRIO, 2000.

D'ACOL, MitiaGanade. Decoro musical e esquemas galantes: um estudo de caso das seções de canto solo das missas de Réquiem de José Maurício Nunes Garcia e Marcos Portugal. Dissertação (Mestrado em Música). São Paulo: Universidade de São Paulo, 2015.

FERNANDES, Angelo José. Missa afro-brasileira de batuque e acalanto: aspectos interpretativos.Dissertação (Mestrado em Música). Campinas: UNICAMP, 2004.

GARCIA, Luís Henrique e PÚBLIO, Hudson Leonardo. (Re)percussões da Missa dos Quilombos. Orfeu. Florianópolis: UDESC, vol. 3, n. 2, dez. de 2018. p.164188.

GOLDBERG, Luis Guilherme. Alberto Nepomuceno e a Missa de Santa Cecília de José Maurício Nunes Garcia. Anais do VI Encontro de Musicologia Histórica. Juiz de Fora, 2004.

GUIMARÃES, Raquel Junqueira. A liturgia do corpo negro na Missa dos Quilombos. Verbo de Minas. Juiz de Fora, vol. 18, n.32, agosto-dezembro de 2017. p. 7995.

MATTOS, Cleofe Person de. José Maurício Nunes Garcia: Biografia. Rio de Janeiro: Biblioteca Nacional, 1997.

MEDEIROS, Ana Judite de Oliveira. Missa de Alcaçus: aproximações melódicas com os romances medievais ibéricos. Dissertação (Mestrado em Ciências Sociais). Natal: Universidade Federal do Rio Grande do Norte, 2014.

MINAMI, Edison. Milton Nascimento e o diálogo inter-religioso na Missa dos Quilombos. Conhecimento \& Diversidade. Niterói: UFF, n. 1, jan.-jun. de 2009. p. 110-122.

OLIVEIRA, Augutos Marcos F. Exxodos e encruzilhadas na Missa dos Quilomobos. Tese (Doutorado em Antropologia Social). Florianópolis: Universidade Federal de Santa Catarina, 2015.

OLIVEIRA, Rosenilton. Orixás: a manifestação cultural de Deus: uma análise das liturgias católicas 'inculturadas"'. Dissertação (Mestrado em Antropologia Social). São Paulo: Universidade de São Paulo, 2008.

QUEIROZ, Rucker Bezerra. O Movimento Armorial em três tempos: aspectos da música nordestina na contextualização dos Quintetos Armorial, da Paraíba e Uirapuru. Tese (Doutorado em Música). Campinas: Universidade Estadual de Campinas, 2014.

RIBALTA, José Luís C. Missa Caiçara: uma abordagem analitico-interpretativa da obra de KilzaSetti. Dissertação (Mestrado em Música). São Paulo: USP, 2011, 2 volumes. 
SILVA, Vladmir. Aspectos estilísticos do repertório coral na obra de Reginaldo Carvalho. Música Hodie. Goiânia: UFG, vol. 9, 2001.

SUASSUNA, Ariano. O Movimento Armorial. Recife. Editora Universitária da UFPE, 1974.

TEIXEIRA, Selma S. Missa dos Quilombos: um canto de Axé. Revista de Letras. Curitiba: UTFPR, v. 1, n. 2, 1997.

VIRMOND, M. C. L.; NOGUEIRA, L. W. M. VeniSancteSpiritus: um moteto de José Maurício Nunes Garcia. Per Musi. Belo Horizonte: UFMG, n.24, 2011.

WAIZBORT, Leopold. Introdução In: WEBER, Max; Fundamentos racionais e sociológicos da música. Trad. deLeopoldo Waizbort. São Paulo: EDUSP, 1995.

WEBER, Max. Fundamentos Racionais e Sociológicos da Música. Trad. Leopoldo Waizbort. São Paulo: EDUSP, 1995.

WEBER, Max. Ensaios de Sociologia. Rio de Janeiro: Guanabara Koogan, 1982.

WEBER, Max. Rejeições Religiosas do Mundo e Suas Direções. In: Ensaios de Sociologia, Ed. Guanabara, Rio de Janeiro, 1982. 


\section{Anexo \\ Algumas missas brasileiras compostas no século $\mathbf{X X}$}

(Muitas poderão ser localizadas por pesquisadores/as no youtube ou em outras plataformas de streaming)

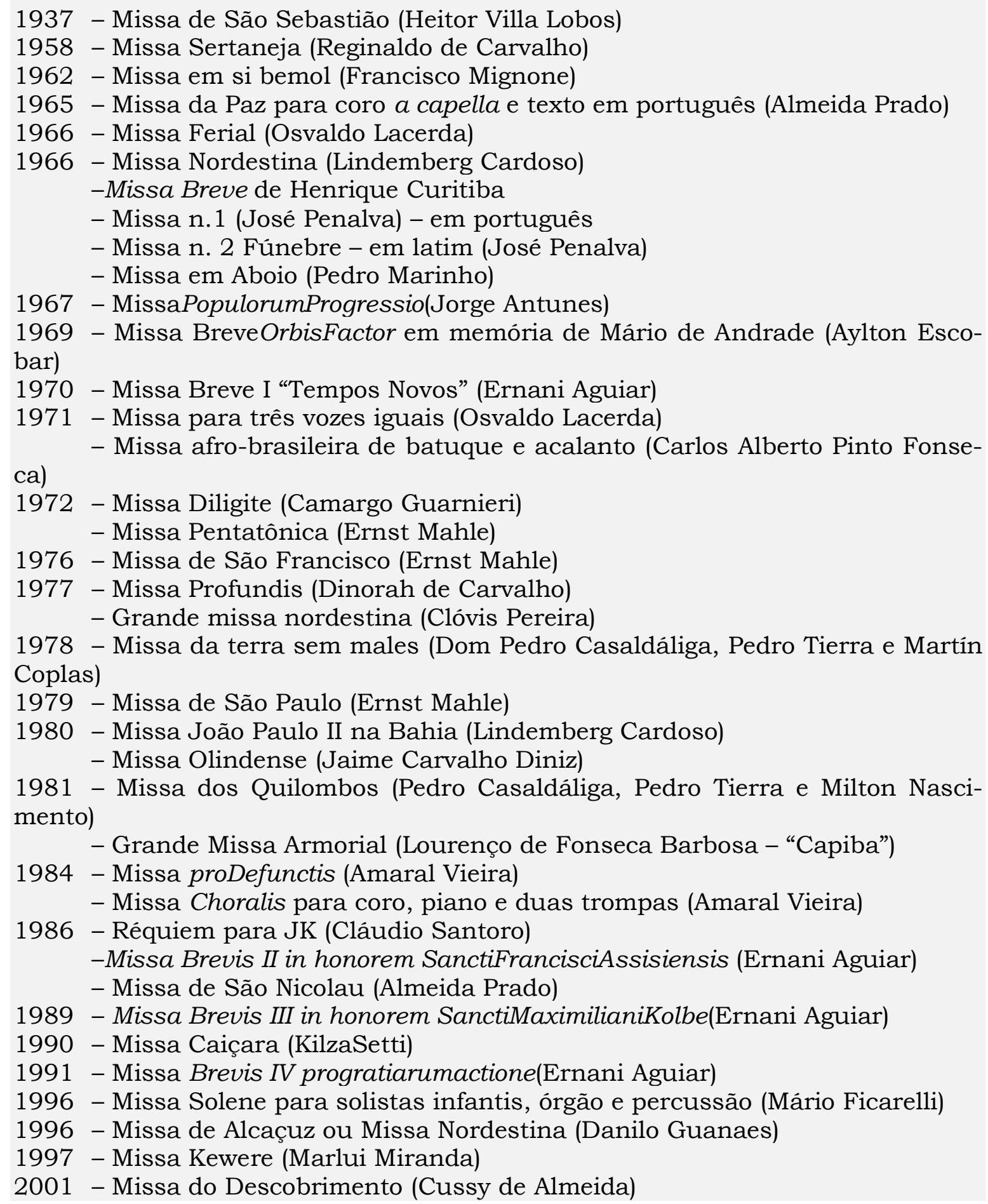


2003 - Missa in Memorian de Arthur Bispo do Rosário (Arrigo Barnabé)

2007 - Missa in Memorian de Itamar Assumpção (Arrigo Barnabé)

2019 - Missa Nóia - os infernos da Cracolândia (Arrigo Barnabé)

Por ser a mais recente, indicamos link Podcast abaixo onde podem ser ouvidos (somente solidtas e coro), sem instrumentação, o Kyrie, Gloria, Santuse Agnus Dei:https:// podcastosesp.podbean.com/?s=Missa+N\%C3\%B3ia

\footnotetext{
1 Optamos por "musicadas" ao invés de "musicalizada", pois essa segunda expressão diz respeito mais propriamente ao processo de iniciação e aprendizado das técnicas musicais.

2 Gravação completa em https://www.youtube.com/watch?v=LTA7rNo-SVU. Acesso em 19 de junho de 2021.

3 Sugestão de audição: https://www.youtube.com/watch?v=NC190-mD2MQ.Acesso em 19 de junho de 2021.

4 Sugestão de audição:https://www.youtube.com/watch?v=1USkS1_YOCE. Acesso em 19 de junho de 2021 .
}

Recebido em 19/06/2021

Aceito para publicação em 24/07/2021 